\title{
Association between Hyperuricemia and Metabolic Syndrome: An Epidemiological Study of a Labor Force Population in Taiwan
}

\author{
Cheng-Yu Wei, ${ }^{1,2,3}$ Chia-Cheng Sun, ${ }^{4}$ James Cheng-Chung Wei, ${ }^{5}$ Hsu-Chih Tai, ${ }^{3}$ \\ Chien-An Sun, ${ }^{6}$ Chian-Fang Chung, ${ }^{7}$ Yu-Ching Chou, ${ }^{8}$ Pi-Li Lin, ${ }^{9}$ and Tsan Yang ${ }^{10}$ \\ ${ }^{1}$ Department of Neurology, Show Chwan Memorial Hospital, Changhua County 50008, Taiwan \\ ${ }^{2}$ Department of Neurology, Chang Bing Show Chwan Memorial Hospital, Changhua County 50544, Taiwan \\ ${ }^{3}$ Department of Exercise and Health Promotion, College of Education, Chinese Culture University, Taipei City 11114, Taiwan \\ ${ }^{4}$ Physical Examination Center, Show Chwan Memorial Hospital, Changhua County 50008, Taiwan \\ ${ }^{5}$ Division of Allergy, Immunology and Rheumatology, Chung Shan Medical University, Taichung City 40201, Taiwan \\ ${ }^{6}$ Department of Public Health, College of Medicine, Fu-Jen Catholic University, New Taipei City 24205, Taiwan \\ ${ }^{7}$ Sleep Center, Chang Bing Show-Chwan Memorial Hospital, Changhua County 50544, Taiwan \\ ${ }^{8}$ School of Public Health, National Defense Medical Center, Taipei City 11490, Taiwan \\ ${ }^{9}$ Department of Nursing, Meiho University, Pingtung County 91202, Taiwan \\ ${ }^{10}$ Department of Health Business Administration, Meiho University, Pingtung County 91202, Taiwan
}

Correspondence should be addressed to Tsan Yang; tsan.yang@msa.hinet.net

Received 12 June 2014; Accepted 26 November 2014

Academic Editor: Yi Liu

Copyright (C) 2015 Cheng-Yu Wei et al. This is an open access article distributed under the Creative Commons Attribution License, which permits unrestricted use, distribution, and reproduction in any medium, provided the original work is properly cited.

\begin{abstract}
The increasing prevalence of metabolic syndrome (MetS) has become an important issue worldwide. Metabolic comorbidities of hypertension, obesity, and hyperlipidemia are shown as important risk factors for incident gout. The purpose of this study was to investigate the relationship between hyperuricemia and MetS. This is a cross-sectional study. The effective sample included 21,544 individuals who received worker health examinations at a local teaching hospital in Changhua County from 2008 2012. We used multiple logistic regression analysis to investigate the influences of hyperuricemia on MetS. The results showed that individuals with MetS had significantly higher blood pressure, fasting plasma glucose, triglycerides, waist circumference, and high-density lipoprotein cholesterol than those without MetS $(P<0.001)$. Multiple logistic regression analysis revealed hyperuricemia to be an important factor of MetS. The risk of developing MetS is higher with high levels of serum uric acid (SUA) and the odds ratio (OR) of having MetS is 4.98 times higher for Tertile 3 than for Tertile 1 (95\% CI $=4.16-5.97)$ and 4 times higher for Quartile 4 than for Quartile $1(95 \% \mathrm{CI}=3.59-4.46)$. In conclusion, males are more likely to develop MetS than females, and the risk of having MetS increases with age and SUA concentration.
\end{abstract}

\section{Introduction}

Gouty arthritis is a common type of chronic arthritis. Hyperuricemia and crystallization of monosodium urate in joints are considered as the important risk factors of gouty arthritis [1]. The relations between hyperuricemia and comorbidities, for instance, hypertension, obesity, and MetS, have been demonstrated in many epidemiologic studies $[2,3]$.
Previous report suggested the high prevalence of MetS in gouty patients, and also it defined the association between insulin resistance and gouty arthritis [4]. Recent studies showed that the prevalence of MetS was high among patients with gout, $44 \%$ in Korean men and $82 \%$ in Mexican men compared with $5 \%$ in the Korean general population [5-7]. Therefore, it is highly suggested to diagnose and treat gout as one of the metabolic diseases [5, 8]. Gout is not considered 
as a simple joint disease and is associated with obesity, cardiovascular disease, hypertension, and MetS with increased mortality [9-11].

There is a tendency for younger individuals to have MetS. Also, MetS is closely related to the occurrence and mortality of chronic conditions such as cardiovascular diseases (CVD), cardiac diseases, diabetes mellitus (DM), and hypertension [12-14].

Epidemiological studies on MetS in different countries and regions show drastically different results. The primary reasons for such drastic differences can be the different characteristics of the participants (e.g., age, ethnicity, socioeconomic status, and abnormal risk factors), the study periods, or different diagnostic definitions. In the United States, the prevalence of MetS is estimated to be $27 \%$ (25.2\% in men and $29 \%$ in women) [15]; and in Taiwan, it is $15.7 \%$ (18.3\% in men and $13.6 \%$ in women) [16].

Previous epidemiological surveys showed that the hyperuricemia is related to the prevalence of MetS $[17,18]$. However, previous studies, for the most part, recruited the general public as research participants and few studies investigated worker populations. Therefore, the purpose of this study was to investigate the relationship between hyperuricemia and MetS in a labor force population. Thus, identifying asymptomatic individuals with a high risk of developing MetS may lead to improvements in prevention and treatment of the condition and of subsequent cardiovascular events and gouty arthritis.

\section{Methods}

We conducted a cross-sectional study on individuals that had undergone worker health screening at a local teaching hospital in Changhua County from 2008 2012. The physical examination document includes physical examination and biochemical blood tests. All individual's examination collecting progress and analysis progress were in accordance with the hospital standard operating procedures, and the laboratory analysis was in accordance with the quality assurance (QA) and quality control (QC). The total sample size was 33,776 with a valid sample size of 21,544 after excluding those with incomplete data on physical examination and biochemical blood tests.

Definition of terms is as follows. (I) In order to understand the current international classification of SUA as criteria of elevated SUA, the present study classified serum SUA levels into (A) SUA $>7.0 \mathrm{mg} / \mathrm{dL}$ for males and SUA > $6.0 \mathrm{mg} / \mathrm{dL}$ for females $[19,20]$; (B) three subgroups in light of the concentration of SUA: (a) SUA $<7 \mathrm{mg} / \mathrm{dL}$, (b) $7 \mathrm{mg} / \mathrm{dL} \leqq$ SUA $<9 \mathrm{mg} / \mathrm{dL}$, and (c) SUA $\geqq 9 \mathrm{mg} / \mathrm{dL}$ [21]; (C) four subgroups among males: (a) SUA $<5 \mathrm{mg} / \mathrm{dL}$, (b) $5 \mathrm{mg} / \mathrm{dL} \leqq$ $\mathrm{SUA}<6 \mathrm{mg} / \mathrm{dL}$, (c) $6 \mathrm{mg} / \mathrm{dL} \leqq \mathrm{SUA}<7 \mathrm{mg} / \mathrm{dL}$, and (d) SUA $\geqq$ $7 \mathrm{mg} / \mathrm{dL}$; and four subgroups among females: (a) SUA < $4 \mathrm{mg} / \mathrm{dL}$, (b) $4 \mathrm{mg} / \mathrm{dL} \leqq \mathrm{SUA}<5 \mathrm{mg} / \mathrm{dL}$, (c) $5 \mathrm{mg} / \mathrm{dL} \leqq \mathrm{SUA}<$ $6 \mathrm{mg} / \mathrm{dL}$, and (d) SUA $\geqq 6 \mathrm{mg} / \mathrm{dL}$ [22]. (II) MetS status was defined according to the criteria set in the Third Report of the National Cholesterol Education Program (NCEP) Expert Panel on Detection, Evaluation, and Treatment of High Blood
Cholesterol in Adults (Adult Treatment Panel III, ATP-III) [23]. We utilized previously established modifications for Asian populations, using waist circumference (WC) cut-off points [24]. Any three of the following five criteria were grounds for identifying MetS: (a) abdominal obesity: WC: $\geqq 90 \mathrm{~cm}$ in men and $\geqq 80 \mathrm{~cm}$ in women; (b) raised triglyceride (TG): $\geqq 150 \mathrm{mg} / \mathrm{dL}$; (c) reduced high-density lipoprotein cholesterol (HDL-C): $<40 \mathrm{mg} / \mathrm{dL}$ in men and $<50 \mathrm{mg} / \mathrm{dL}$ in women; (d) raised blood pressure (BP): BP of at least $130 / 85 \mathrm{mmHg}$ or taking antihypertensive medication; and (e) raised fasting plasma glucose (FPG): $\geqq 110 \mathrm{mg} / \mathrm{dL}$ and/or taking antiglycemic medication.

The physical examination comprised BP and anthropometric measurements, including height, weight, and body mass index (BMI). Height was measured to the nearest $0.1 \mathrm{~cm}$, without shoes, using a stadiometer. Weight was measured in light clothing, without shoes, using a beam balance scale, and was recorded to the nearest $0.1 \mathrm{~kg}$. BMI was calculated as weight $(\mathrm{kg})$ divided by height ${ }^{2}\left(\mathrm{~m}^{2}\right)$. Well-trained nurses measured systolic BP (SBP) and diastolic BP (DBP) two times in the left arm of seated participants, according to a standardized protocol. A third BP measurement was made if the first two $\mathrm{BP}$ readings differed by more than $10 \mathrm{~mm} \mathrm{Hg}$. The average of the two closest readings was calculated to determine the reported $\mathrm{BP}$ for each participant. The items in the blood examination included TG, SUA, FPG, and HDL-C. The sample was venous blood drawn after 8 hours of fasting and was sent to the lab within an hour and analyzed by a Hitachi7070 biochemical analyzer.

Data in the present study were analyzed using SPSS 17.0 (SPSS for Windows release 17.0), with a significance level of $\alpha=0.05$. Descriptive statistics used the average value, the standard deviation, the frequency distribution, and the percentage criterion. Inferential statistics used the Chi-square and multiple logistic regression models for analysis.

\section{Results}

Study participants included 21,544 individuals aged over 21 who were receiving a worker health examination in Changhua County. The mean age was $38.4 \pm 9.5$, with 4,881 individuals $(27.0 \%)$ in the range of $21-30$ years old, 8,940 $(41.5 \%)$ individuals in the range of $31-40$ years old, 4,780 $(22.2 \%)$ individuals in the range of $41-50$ years old, and 2,943 $(13.7 \%)$ individuals over 51 years old. The majority of the participants were male, with 13,009 males $(60.4 \%)$ and 8,535 females (39.6\%).

Demographic characteristics such as age and gender differed significantly between individuals with and without MetS $(P<0.001)$. Individuals at an older age had high prevalence of MetS, and males had higher prevalence of MetS than females (15.8\% versus $6.7 \%)$. There were significantly higher ratios of abnormal $\mathrm{BP}, \mathrm{FPG}, \mathrm{TG}, \mathrm{WC}$, and $\mathrm{HDL}-\mathrm{C}$ in individuals with MetS than in those without MetS; the ratios were $28.0 \%, 60.5 \%, 44.7 \%, 37.8 \%$, and $49.8 \%$, respectively (Table 1).

The ratio of hyperuricemia in individuals with MetS was $24.7 \%$, which is significantly higher than the $8.3 \%$ in 
TABLE 1: Correlation analysis of demographic characteristics, biochemistry exam results, and metabolic syndrome $(n=21,544)$.

\begin{tabular}{|c|c|c|c|c|c|}
\hline \multirow{2}{*}{ Variables } & \multicolumn{2}{|c|}{ No MetS $(n=18,927,87.9 \%)$} & \multicolumn{2}{|c|}{ MetS $(n=2617,12.1 \%)$} & \multirow{2}{*}{$P$ value } \\
\hline & Number & Percentage & Number & Percentage & \\
\hline Gender & & & & & $<0.001$ \\
\hline Male & 10960 & 84.2 & 2049 & 15.8 & \\
\hline Female & 7967 & 93.3 & 568 & 6.7 & \\
\hline Age (years) & & & & & $<0.001$ \\
\hline $21-30$ & 4631 & 94.9 & 250 & 5.1 & \\
\hline $31-40$ & 7935 & 88.8 & 1005 & 11.2 & \\
\hline $41-50$ & 4034 & 84.4 & 746 & 15.6 & \\
\hline$\geqq 51$ & 2327 & 79.1 & 753 & 20.9 & \\
\hline $\mathrm{WC}(\mathrm{cm})$ & & & & & $<0.001$ \\
\hline Normal & 15327 & 97.3 & 431 & 2.7 & \\
\hline Abnormal (male: $\geqq 90$; female: $\geqq 80$ ) & 3600 & 62.2 & 2186 & 37.8 & \\
\hline Raised blood pressure $(\mathrm{mmHg})^{\mathrm{a}}$ & & & & & $<0.001$ \\
\hline Normal & 13016 & 97.6 & 316 & 2.4 & \\
\hline Abnormal $(\geqq 130 / 85)$ & 5911 & 72.0 & 2301 & 28.0 & \\
\hline TG (mg/dL) & & & & & $<0.001$ \\
\hline Normal & 16227 & 97.4 & 436 & 2.6 & \\
\hline Abnormal $(\geqq 150)$ & 2700 & 55.3 & 2181 & 44.7 & \\
\hline Raised FPG (mg/dL) ${ }^{\mathrm{b}}$ & & & & & $<0.001$ \\
\hline Normal & 18524 & 90.3 & 1999 & 9.7 & \\
\hline Abnormal $(\geqq 110)$ & 403 & 39.5 & 618 & 60.5 & \\
\hline HDL-C (mg/dL) & & & & & $<0.001$ \\
\hline Normal & 17547 & 93.4 & 1247 & 6.6 & \\
\hline Abnormal ( $<40$ in men and $<50$ in women) & 1380 & 50.2 & 1370 & 49.8 & \\
\hline
\end{tabular}

Note. Analyzed by Chi-square test, 2-tailed test, and significance level $\alpha=.05$.

${ }^{\mathrm{a}}$ Raised blood pressure $\geqq 130 / 85 \mathrm{mmHg}$ or currently taking antihypertensive drugs.

${ }^{\mathrm{b}}$ Raised fasting plasma glucose $\geqq 110 \mathrm{mg} / \mathrm{dL}$ or currently taking oral hypoglycemic agent.

individuals without MetS $(P<0.001)$. After dividing the SUA concentration into 3 groups, we found that Tertile 3 had an abnormally high ratio of SUA compared to Tertiles 2 and 1 (35.3\% versus $22.9 \%$ and $8.4 \%$ ). In addition, we divided SUA concentration into 4 groups, and we found that Quartile 4 had a significantly and abnormally high ratio of SUA compared to Quartile $1(24.0 \%$ versus 5.6\%) $(P<0.001)$ (Table 2$)$.

In this study, we added variables that were statistically significant by univariate analysis (i.e., age, gender, and SUA) into multiple logistic regression analysis. The results (Table 3 ) show that SUA was a significant contributing factor to MetS in multiple logistic regression models I, II, and III. For model I, the OR of individuals with hyperuricemia having MetS was 3.08 times that of individuals with normal SUA $(95 \%$ CI = 2.82-3.37). With increased age, the ORs of having MetS increased accordingly. For example, the OR of individuals over 51 years old having MetS was 4.46 times that of individuals $21-30$ years old ( $95 \% \mathrm{CI}=3.81-5.23)$, and the OR of males having MetS was 1.80 times that of females $(95 \% \mathrm{CI}=$ 1.63-2.00). These ORs are all statistically significant $(P<$ 0.001 ). For model II, we divided the SUA concentration into 3 groups and found that a higher SUA concentration was associated with a higher risk of MetS. For those individuals with SUA $\geqq 9 \mathrm{mg} / \mathrm{dL}$, the risk of having MetS was 4.98 times higher $(95 \% \mathrm{CI}=4.16-5.97)$. With increased age, the odds of MetS increased 2.24 4.59 times (ORs $=2.24 \sim 4.59)$. Males had 1.59 times higher OR of MetS than females (95\% CI $=1.42-1.77$ ). In addition, in model III, we divided the SUA concentration into 4 groups and found that a higher SUA concentration was associated with a higher risk of MetS. Individuals with a SUA concentration in the Quartile 3 and Quartile 4 groups had 1.70 4.00 times ORs of MetS, and the ORs associated with increased age were 2.25 4.48 times. As for gender as a risk factor, males had a risk of developing MetS that was 1.65 times (95\% CI $=1.49-1.83$ ) higher, and significantly so, than that of females $(P<0.001)$.

\section{Discussion}

Studies show that hyperuricemia not only can cause gout, but also is a high risk factor for atherosclerotic diseases such as CVD and carotid atherosclerosis [25], hypertension [26], DM [27], MetS [28], and cardiac diseases and chronic diseases such as cerebral vascular diseases. Further analysis showed that elevated SUA is associated with a higher risk of developing CVD and mortality as a result of CVD [29]. Our study shows that MetS is associated with age, and increased age is associated with a higher rate of MetS. We observed that individuals over 51 years old had the prevalence rate of $20.9 \%$ of developing MetS. Our result is consistent with many previous 
TABLE 2: Correlation analysis of hyperuricemia and metabolic syndrome $(n=21,544)$.

\begin{tabular}{|c|c|c|c|c|c|}
\hline \multirow{2}{*}{ Variable } & \multicolumn{2}{|c|}{ No MetS $(n=18,927,87.9 \%)$} & \multicolumn{2}{|c|}{ MetS $(n=2617,12.1 \%)$} & \multirow{2}{*}{$P$ value } \\
\hline & Number & Percentage & Number & Percentage & \\
\hline Hyperuricemia & & & & & $<0.001$ \\
\hline Normal & 15074 & 91.7 & 1356 & 8.3 & \\
\hline Abnormal $($ male $>7$; female $>6 \mathrm{mg} / \mathrm{dL})$ & 3853 & 75.3 & 1261 & 24.7 & \\
\hline Subgroups of SUA ${ }^{\mathrm{a}}$ & & & & & $<0.001$ \\
\hline Tertile 1 & 15190 & 91.6 & 1402 & 8.4 & \\
\hline Tertile 2 & 3325 & 77.1 & 990 & 22.9 & \\
\hline Tertile 3 & 412 & 64.7 & 225 & 35.3 & \\
\hline Subgroups of SUA ${ }^{b}$ & & & & & $<0.001$ \\
\hline Quartile 1 & 3274 & 94.4 & 194 & 5.6 & \\
\hline Quartile 2 & 6007 & 93.6 & 411 & 6.4 & \\
\hline Quartile 3 & 5406 & 88.9 & 673 & 11.1 & \\
\hline Quartile 4 & 4240 & 76.0 & 1339 & 24.0 & \\
\hline
\end{tabular}

Note. Analyzed by Chi-square test, 2-tailed test, and significance level $\alpha=.05$.

${ }^{\text {a }}$ Subgroups of SUA Tertile 1: SUA $<7 \mathrm{mg} / \mathrm{dL}$, Tertile $2: 7 \mathrm{mg} / \mathrm{dL} \leqq \mathrm{SUA}<9 \mathrm{mg} / \mathrm{dL}$ and Tertile $3: \mathrm{SUA} \geqq 9 \mathrm{mg} / \mathrm{dL}$.

${ }^{\mathrm{b}}$ Subgroups of SUA Quartile 1: male SUA $<5 \mathrm{mg} / \mathrm{dL}$, female SUA $<4 \mathrm{mg} / \mathrm{dL}$; Quartile 2: male $5 \mathrm{mg} / \mathrm{dL} \leqq \mathrm{SUA}<6 \mathrm{mg} / \mathrm{dL}$, female $4 \mathrm{mg} / \mathrm{dL} \leqq \mathrm{SUA}<5 \mathrm{mg} / \mathrm{dL}$; Quartile 3: male $6 \mathrm{mg} / \mathrm{dL} \leqq \mathrm{SUA}<7 \mathrm{mg} / \mathrm{dL}$, female $5 \mathrm{mg} / \mathrm{dL} \leqq \mathrm{SUA}<6 \mathrm{mg} / \mathrm{dL}$; and Quartile 4 : male SUA $\geqq 7 \mathrm{mg} / \mathrm{dL}$, female SUA $\geqq 6 \mathrm{mg} / \mathrm{dL}$.

TABLE 3: Regression analysis of risk factors of metabolic syndrome.

\begin{tabular}{|c|c|c|c|c|}
\hline Item & $\beta$ & Wald & OR (95\% CI) & $P$ value \\
\hline \multicolumn{5}{|l|}{ Model I } \\
\hline Gender $^{\mathrm{a}}$ & 0.59 & 127.37 & $1.80(1.63-2.00)$ & $<0.001$ \\
\hline Age $2^{\mathrm{b}}$ & 0.80 & 117.39 & $2.23(1.93-2.58)$ & $<0.001$ \\
\hline Age $3^{\mathrm{b}}$ & 1.21 & 246.29 & $3.38(2.90-3.39)$ & $<0.001$ \\
\hline Age $4^{\mathrm{b}}$ & 1.49 & 342.42 & $4.46(3.81-5.23)$ & $<0.001$ \\
\hline Hyperuricemia $^{c}$ & 1.12 & 616.32 & $3.08(2.82-3.37)$ & $<0.001$ \\
\hline \multicolumn{5}{|l|}{ Model II } \\
\hline Gender & 0.46 & 70.50 & $1.59(1.42-1.77)$ & $<0.001$ \\
\hline Age 2 & 0.80 & 118.71 & $2.24(1.94-2.59)$ & $<0.001$ \\
\hline Age 3 & 1.22 & 249.78 & $3.41(2.92-3.97)$ & $<0.001$ \\
\hline Age 4 & 1.52 & 354.88 & $4.59(3.92-5.38)$ & $<0.001$ \\
\hline Tertile $2^{\mathrm{d}}$ & 0.98 & 383.48 & $2.67(2.42-2.95)$ & $<0.001$ \\
\hline Tertile $3^{\mathrm{d}}$ & 1.60 & 305.04 & $4.98(4.16-5.97)$ & $<0.001$ \\
\hline \multicolumn{5}{|l|}{ Model III } \\
\hline Gender & 0.50 & 90.08 & $1.65(1.49-1.83)$ & $<0.001$ \\
\hline Age 2 & 0.81 & 119.36 & $2.25(1.94-2.60)$ & $<0.001$ \\
\hline Age 3 & 1.22 & 247.95 & $3.40(2.92-3.96)$ & $<0.001$ \\
\hline Age 4 & 1.50 & 344.13 & $4.48(3.82-5.25)$ & $<0.001$ \\
\hline Quartile $3^{\mathrm{e}}$ & 0.53 & 78.90 & $1.70(1.51-1.91)$ & $<0.001$ \\
\hline Quartile $4^{\mathrm{e}}$ & 1.38 & 625.44 & $4.00(3.59-4.46)$ & $<0.001$ \\
\hline
\end{tabular}

Note1. Analyzed by stepwise regression analysis. Considered variables include age, gender, and SUA.

Note2. Dependent variable: MetS, 1, with MetS; 0, without MetS.

${ }^{\mathrm{a}}$ Gender: female $=0,{ }^{\mathrm{b}}$ age: $21-30=0$.

${ }^{c}$ Abnormal (male $>7$; female $\left.>6 \mathrm{mg} / \mathrm{dL}\right)=1$; normal $=0$.

${ }^{\mathrm{d}}$ Subgroups of SUA Tertile 1: SUA $<7 \mathrm{mg} / \mathrm{dL}$, Tertile $2: 7 \mathrm{mg} / \mathrm{dL} \leqq \mathrm{SUA}<9 \mathrm{mg} / \mathrm{dL}$ and Tertile $3:$ SUA $\geqq 9 \mathrm{mg} / \mathrm{dL}$.

${ }^{e}$ subgroups of SUA Quartile 1: male SUA $<5 \mathrm{mg} / \mathrm{dL}$ and female SUA $<4 \mathrm{mg} / \mathrm{dL}$.

Quartile 2: male $5 \mathrm{mg} / \mathrm{dL} \leqq \mathrm{SUA}<6 \mathrm{mg} / \mathrm{dL}$ and female $4 \mathrm{mg} / \mathrm{dL} \leqq \mathrm{SUA}<5 \mathrm{mg} / \mathrm{dL}$.

Quartile 3: male $6 \mathrm{mg} / \mathrm{dL} \leqq \mathrm{SUA}<7 \mathrm{mg} / \mathrm{dL}$ and female $5 \mathrm{mg} / \mathrm{dL} \leqq \mathrm{SUA}<6 \mathrm{mg} / \mathrm{dL}$.

Quartile 4 : male SUA $\geqq 7 \mathrm{mg} / \mathrm{dL}$ and female $S U A \geqq 6 \mathrm{mg} / \mathrm{dL}$. 
studies that show that the prevalence of MetS increases with increased age [30]. We also found that males have a higher rate of MetS than females (15.8\% versus 6.7\%), a result similar to other studies. For example, Balkau et al. (2003) found that prevalence rates of MetS in males and females among 4,293 individuals in the 2001 French National Cholesterol Education Program were $10 \%$ and $7 \%$, respectively [31]. Hu et al. (2004) found that among 11,512 Europeans aged from 30 to 89 who did not have DM males had higher prevalence of MetS than females (15.7\% versus 14.2\%) [32]. Chuang et al. (2004) found that among those receiving health examinations in Taipei City males had higher prevalence of MetS than females (15.5\% versus $10.5 \%)$. The prevalence rates were $15.7 \%$ versus $12.0 \%$ after correcting for variables [33].

MetS is commonly accompanied with hypertension, type II DM, hyperlipidemia, stroke, or CVD. MetS is a cluster of three diseases-hypertension, hyperglycemia, and gout. At present, its etiological mechanisms are yet to be understood. But it is clear that MetS is associated with obesity, insulin resistance, and abnormal blood lipids that lead to the abovedescribed three diseases [34]. From our study, it is obvious that individuals with MetS have a significantly higher ratio of abnormal BP, FPG, TG, WC, and HDL-C than those without MetS.

To understand the effects of SUA concentration on MetS, we used multiple logistic regression and conducted analyses using three models, I, II, and III, based on SUA concentration. Variables that showed statistically significant differences in univariate analysis (i.e., age, gender, and SUA) were used in regression models. For different regression models, after controlling other variables, the results showed that the OR of individuals with abnormal SUA having MetS was 3.08 times $(95 \% \mathrm{CI}=2.82-3.37)$ that of individuals with normal SUA in model I. In models II and III, the ORs of having MetS were higher in those with an elevated SUA concentration, with ORs of $2.65-4.98$ and $1.70-4.00$, respectively.

A large-scale epidemiological study reported that elevated SUA concentrations are associated with an increased mortality rate; further analyses showed that hyperuricemia seems to be related to hypertension, obesity, MetS, renal diseases, and CVD [35]. A recent study supported the role of SUA itself as an independent risk factor for CVD [26]. Previous studies reached similar conclusions that SUA is significantly associated with cardiovascular risk factors such as hypertension [36], MetS [37], and insulin resistance [38]. Other studies also found that high SUA concentrations are associated with an increased risk of MetS [39]. Follow-up analysis of American residents with hyperuricemia found that males with a SUA value $\geqq 6.5 \mathrm{mg} / \mathrm{dL}$ had a 1.6 times higher risk of developing MetS than males with a value $<5.5 \mathrm{mg} / \mathrm{dL}$, and females with a SUA value $\geqq 4.6 \mathrm{mg} / \mathrm{dL}$ had a 2 times greater risk of developing MetS.

Although the relationship between hyperuricemia and CVD was established in the 19th century, there is still controversy as to whether hyperuricemia plays a role as an indicator or a risk factor [40]. The strong relationship between hyperuricemia and other cardiovascular risk factors such as hypertension, insulin resistance, obesity, and renal insufficiency makes it difficult to establish a causal relationship in epidemiological studies. Recent experiments have made significant contributions in providing important knowledge pertaining to the pathological meaning of hyperuricemia. Symptoms resulting from hyperuricemia can be alleviated by xanthine-oxidase inhibitors or uricosuric agents that reduce SUA concentrations [41]. These results show that lowering SUA can play an important role in preventing CVD. The consensus is that MetS can be considered as a predictive factor for CVD [14]. The traditional view is that impaired renal clearance induced by compensatory hyperinsulinemia can cause hyperuricemia [42]. However, recent studies provide a different perspective, implying that hyperuricemia can be an independent factor predicting the occurrence of MetS and DM, even after controlling for different genders and basic BMI [28].

The findings in previously described studies are similar to those in our study. That is, SUA concentration can be used as an important predictive factor for MetS. The risk of MetS increases with elevated SUA concentrations.

Admittedly, with the cross-sectional nature of this study, it is not possible to establish a causal relationship between hyperuricemia and MetS. This study could not eliminate the potential effects of underlying diseases, medications used, and dietary habits for these diseases among participants on the present findings. It is possible that residual confounding by these factors may also affect the MetS and SUA link. Further population-based prospective studies are needed to elucidate a cause-effect relationship between hyperuricemia and MetS. By using these epidemiologic study findings, it will bring more benefits for health management and prevention of clinical disease.

In conclusion, although hyperuricemia is still not one of the determining factors for MetS, more and more studies are showing that high SUA concentrations are associated with and have negative effects on CVD, insulin resistance, hypertension, and abdominal obesity. Our study also showed that individuals with MetS have higher ratio of having abnormal BP, FPG, TG, WC, and HDL-C than those without MetS. Age, gender, and abnormal SUA were risk factors for MetS as analyzed by the multiple logistic regression models. In addition, a higher SUA concentration is associated with a higher risk of MetS, no matter if the SUA concentrations were divided into three or four groups.

We recommend that dietitians should pay attention to the SUA value in individuals receiving health education for their MetS-related diseases. Related health education should be provided when necessary. As for patients who only have hyperuricemia, dietary health education that is related to MetS should be provided to help the patients control their uric acid value better.

\section{Conflict of Interests}

The authors declare that there is no conflict of interests regarding the publication of this paper.

\section{Acknowledgments}

This study was supported by a grant from the Chang Bing Show Chwan Memorial Hospital (RD101040). The authors 
would specifically like to thank the Department of Health Center for administrative support and data collection.

\section{References}

[1] J. D. Bieber and R. A. Terkeltaub, "Gout: on the brink of novel therapeutic options for an ancient disease," Arthritis and Rheumatism, vol. 50, no. 8, pp. 2400-2414, 2004.

[2] P. Richette and T. Bardin, "Gout," The Lancet, vol. 375, no. 9711, pp. 318-328, 2010.

[3] H. K. Choi, E. S. Ford, C. Li, and G. Curhan, "Prevalence of the metabolic syndrome in patients with gout: the Third National Health and Nutrition Examination Survey," Arthritis Care and Research, vol. 57, no. 1, pp. 109-115, 2007.

[4] H. G. Yoo, S. I. Lee, H. J. Chae, S. J. Park, Y. C. Lee, and W. H. Yoo, "Prevalence of insulin resistance and metabolic syndrome in patients with gouty arthritis," Rheumatology International, vol. 31, no. 4, pp. 485-491, 2011.

[5] J. Vázquez-Mellado, C. García García, S. Guzmán Vázquez et al., "Metabolic syndrome and ischemic heart disease in gout," Journal of Clinical Rheumatology, vol. 10, no. 3, pp. 105-109, 2004.

[6] Y. H. Rho, S. J. Choi, Y. H. Lee et al., "The prevalence of metabolic syndrome in patients with gout: a multicenter study," Journal of Korean Medical Science, vol. 20, no. 6, pp. 1029-1033, 2005.

[7] W.-Y. Lee, J.-S. Park, S.-Y. Noh, E.-J. Rhee, S.-W. Kim, and P. Z. Zimmet, "Prevalence of the metabolic syndrome among 40,698 Korean metropolitan subjects," Diabetes Research and Clinical Practice, vol. 65, no. 2, pp. 143-149, 2004.

[8] Y. H. Rho, S. J. Choi, Y. H. Lee et al., "Prevalence of the metabolic syndrome in patients with gout," The Journal of the Korean Rheumatism Association, vol. 11, pp. 349-357, 2004.

[9] B. Emmerson, "Hyperlipidaemia in hyperuricaemia and gout," Annals of the Rheumatic Diseases, vol. 57, no. 9, pp. 509-510, 1998.

[10] A. G. Fam, "Gout, diet, and the insulin resistance syndrome," Journal of Rheumatology, vol. 29, no. 7, pp. 1350-1355, 2002.

[11] H. K. Choi, D. B. Mount, and A. M. Reginato, "Pathogenesis of gout," Annals of Internal Medicine, vol. 143, no. 7, pp. 499-516, 2005.

[12] R. H. Eckel, K. Alberti, S. M. Grundy, and P. Z. Zimmet, "The metabolic syndrome," The Lancet, vol. 375, no. 9710, pp. 181-183, 2010.

[13] L. C. Hwang and K. C. Huang, "Definition and epidemiology of metabolic syndrome," Formosan Journal of Medicine, vol. 11, pp. 363-369, 2007.

[14] P. W. F. Wilson, R. B. D’Agostino, H. Parise, L. Sullivan, and J. B. Meigs, "Metabolic syndrome as a precursor of cardiovascular disease and type 2 diabetes mellitus," Circulation, vol. 112, no. 20, pp. 3066-3072, 2005.

[15] E. S. Ford, W. H. Giles, and A. H. Mokdad, "Increasing prevalence of the metabolic syndrome among U.S. adults," Diabetes Care, vol. 27, no. 10, pp. 2444-2449, 2004.

[16] L.-C. Hwang, C.-H. Bai, and C.-J. Chen, "Prevalence of obesity and metabolic syndrome in Taiwan," Journal of the Formosan Medical Association, vol. 105, no. 8, pp. 626-635, 2006.

[17] M. Reimann, A. E. Schutte, L. Malan, H. W. Huisman, and N. T. Malan, "Hyperuricaemia is an independent factor for the metabolic syndrome in a sub-Saharan African population: a factor analysis," Atherosclerosis, vol. 197, no. 2, pp. 638-645, 2008.
[18] P.-W. Liu, T.-Y. Chang, and J.-D. Chen, "Serum uric acid and metabolic syndrome in Taiwanese adults," Metabolism: Clinical and Experimental, vol. 59, no. 6, pp. 802-807, 2010.

[19] C.-S. Lin, Y.-J. Hung, G.-Y. Chen et al., "A multicenter study of the association of serum uric acid, serum creatinine, and diuretic use in hypertensive patients," International Journal of Cardiology, vol. 148, no. 3, pp. 325-330, 2011.

[20] H. Sonoda, H. Takase, Y. Dohi, and G. Kimura, "Uric acid levels predict future development of chronic kidney disease," The American Journal of Nephrology, vol. 33, no. 4, pp. 352-357, 2011.

[21] R. P. Obermayr, C. Temml, G. Gutjahr, M. Knechtelsdorfer, R. Oberbauer, and R. Klauser-Braun, "Elevated uric acid increases the risk for kidney disease," Journal of the American Society of Nephrology, vol. 19, no. 12, pp. 2407-2413, 2008.

[22] H.-Y. Chang, C.-W. Tung, P.-H. Lee et al., "Hyperuricemia as an independent risk factor of chronic kidney disease in middleaged and elderly population," American Journal of the Medical Sciences, vol. 339, no. 6, pp. 509-515, 2010.

[23] J. I. Cleeman, "Executive summary of the third report of the National Cholesterol Education Program (NCEP) expert panel on detection, evaluation, and treatment of high blood cholesterol in adults (adult treatment panel III)," The Journal of the American Medical Association, vol. 285, no. 19, pp. 24862497, 2001.

[24] C. E. Tan, S. Ma, D. Wai, S. K. Chew, and E. S. Tai, "Can we apply the National Cholesterol Education Program adult treatment panel definition of the metabolic syndrome to Asians?" Diabetes Care, vol. 27, no. 5, pp. 1182-1186, 2004.

[25] R. Kawamoto, H. Tomita, Y. Oka, A. Kodama, and A. Kamitani, "Metabolic syndrome amplifies the LDL-cholesterol associated increases in carotid atherosclerosis," Internal Medicine, vol. 44, no. 12, pp. 1232-1238, 2006.

[26] R. J. Johnson, D.-H. Kang, D. Feig et al., "Is there a pathogenetic role for uric acid in hypertension and cardiovascular and renal disease?" Hypertension, vol. 41, no. 6, pp. 1183-1190, 2003.

[27] K.-L. Chien, M.-F. Chen, H.-C. Hsu et al., "Plasma uric acid and the risk of type 2 diabetes in a Chinese community," Clinical Chemistry, vol. 54, no. 2, pp. 310-316, 2008.

[28] X. Sui, T. S. Church, R. A. Meriwether, F. Lobelo, and S. N. Blair, "Uric acid and the development of metabolic syndrome in women and men," Metabolism: Clinical and Experimental, vol. 57, no. 6, pp. 845-852, 2008.

[29] J.-H. Chen, S.-Y. Chuang, H.-J. Chen, Y. E. H. Wen-Ting, and P. A. N. Wen-Harn, "Serum uric acid level as an independent risk factor for all-cause, cardiovascular, and ischemic stroke mortality: a chinese cohort study," Arthritis Care and Research, vol. 61, no. 2, pp. 225-232, 2009.

[30] L. C. Hawang, C. H. Bai, C. J. Chen, and K. L. Chien, "Gender different on the development of metabolic syndrome: a population-based study in Taiwan," European Journal of Epidemiology, vol. 22, pp. 2486-2497, 2007.

[31] B. Balkau, M. Vernay, L. Mhamdi et al., "The incidence and persistence of the NCEP (National Cholesterol Education Program) metabolic syndrome. The French D.E.S.I.R. study," Diabetes and Metabolism, vol. 29, no. 5, pp. 526-532, 2003.

[32] G. Hu, Q. Qiao, J. Tuomilehto, B. Balkau, K. Borch-Johnsen, and K. Pyorala, "Prevalence of the metabolic syndrome and its relation to all-cause and cardiovascular mortality in nondiabetic European men and women," Archives of Internal Medicine, vol. 164, no. 10, pp. 1066-1076, 2004.

[33] S.-Y. Chuang, C.-H. Chen, and P. Chou, "Prevalence of metabolic syndrome in a large health check-up population in 
Taiwan," Journal of the Chinese Medical Association, vol. 67, no. 12, pp. 611-620, 2004.

[34] Y. C. Yang and C. J. Chang, "Metabolic syndrome, obesity and diabetes," Formosan Journal of Medicine, vol. 11, pp. 370-380, 2007.

[35] J. Fang and M. H. Alderman, "Serum uric acid and cardiovascular mortality: the NHANES I epidemiologic follow-up study, 1971-1992," Journal of the American Medical Association, vol. 283, no. 18, pp. 2404-2410, 2000.

[36] P. B. Mellen, A. J. Bleyer, T. P. Erlinger et al., "Serum uric acid predicts incident hypertension in a biethnic cohort: the Atherosclerosis Risk in Communities study," Hypertension, vol. 48, no. 6, pp. 1037-1042, 2006.

[37] E. S. Ford, C. Li, S. Cook, and H. K. Choi, "Serum concentrations of uric acid and the metabolic syndrome among US children and adolescents," Circulation, vol. 115, no. 19, pp. 25262532, 2007.

[38] L.-K. Chen, M.-H. Lin, H.-Y. Lai, S.-J. Hwang, and S.-T. Chiou, "Uric acid: a surrogate of insulin resistance in older women," Maturitas, vol. 59, no. 1, pp. 55-61, 2008.

[39] M. S. Lee, S. C. Lin, H. Y. Chang, L. C. Lyu, K. S. Tsai, and W. H. Pan, "High prevalence of hyperuricemia in elderly Taiwanese," Asia Pacific Journal of Clinical Nutrition, vol. 14, no. 3, pp. 285292, 2005.

[40] T. Nakagawa, D.-H. Kang, D. Feig et al., "Unearthing uric acid: an ancient factor with recently found significance in renal and cardiovascular disease," Kidney International, vol. 69, no. 10, pp. 1722-1725, 2006.

[41] D. B. Corry, P. Eslami, K. Yamamoto, M. D. Nyby, H. Makino, and M. L. Tuck, "Uric acid stimulates vascular smooth muscle cell proliferation and oxidative stress via the vascular reninangiotensin system," Journal of Hypertension, vol. 26, no. 2, pp. 269-275, 2008.

[42] F. Facchini, Y.-D. I. Chen, C. B. Hollenbeck, and G. M. Reaven, "Relationship between resistance to insulin-mediated glucose uptake, urinary uric acid clearance, and plasma uric acid concentration," The Journal of the American Medical Association, vol. 266, no. 21, pp. 3008-3011, 1991. 


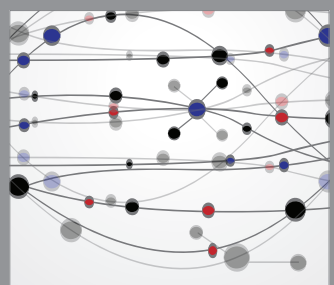

The Scientific World Journal
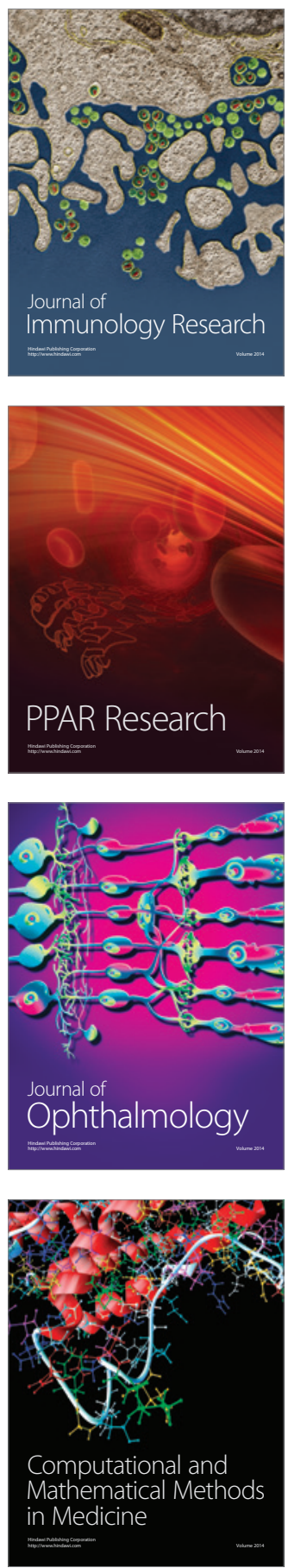

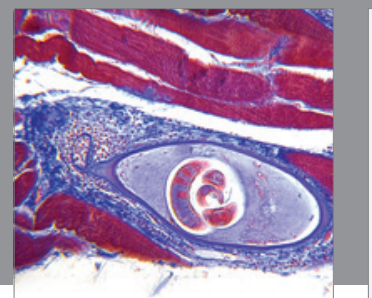

Gastroenterology

Research and Practice
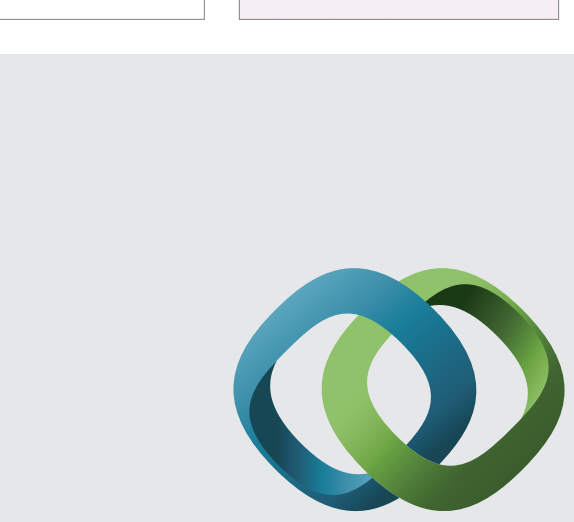

\section{Hindawi}

Submit your manuscripts at

http://www.hindawi.com
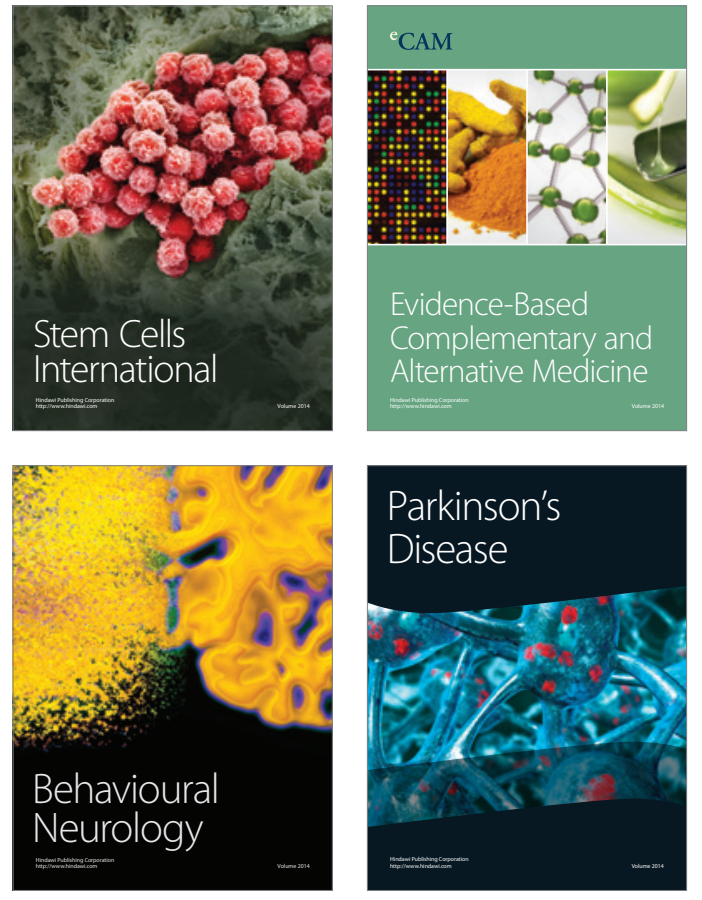
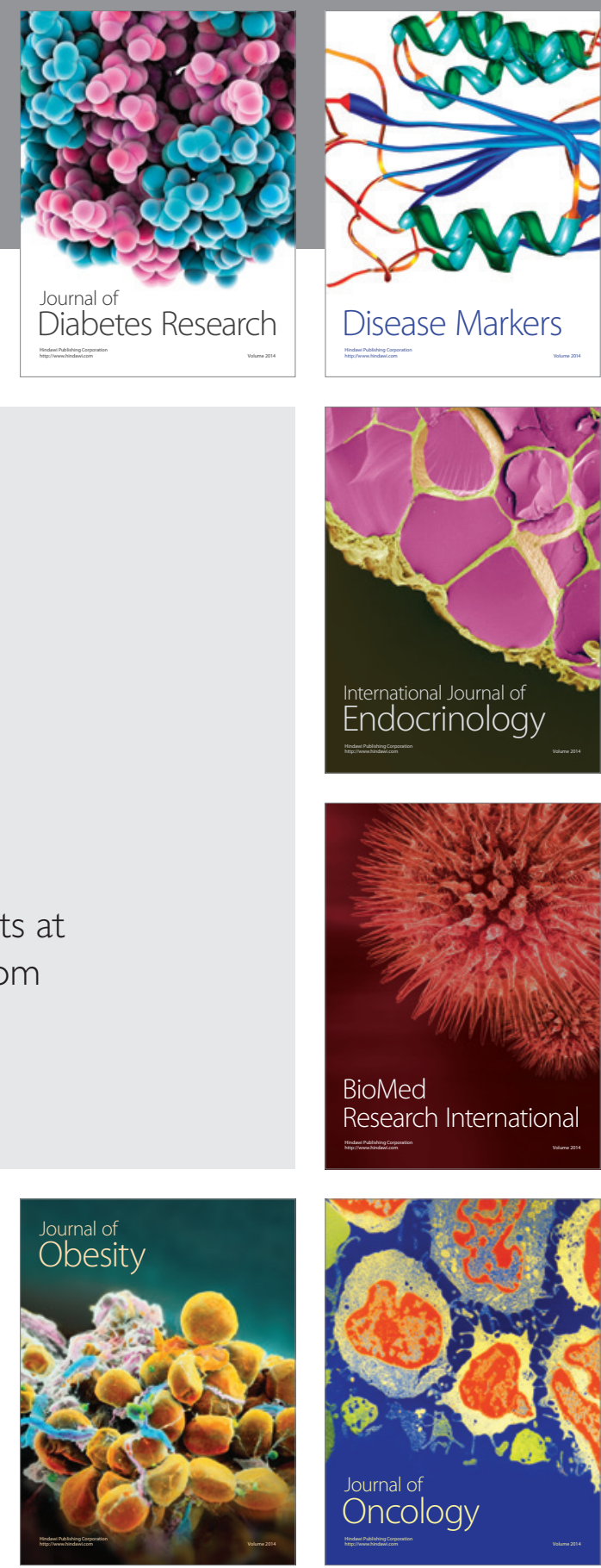

Disease Markers
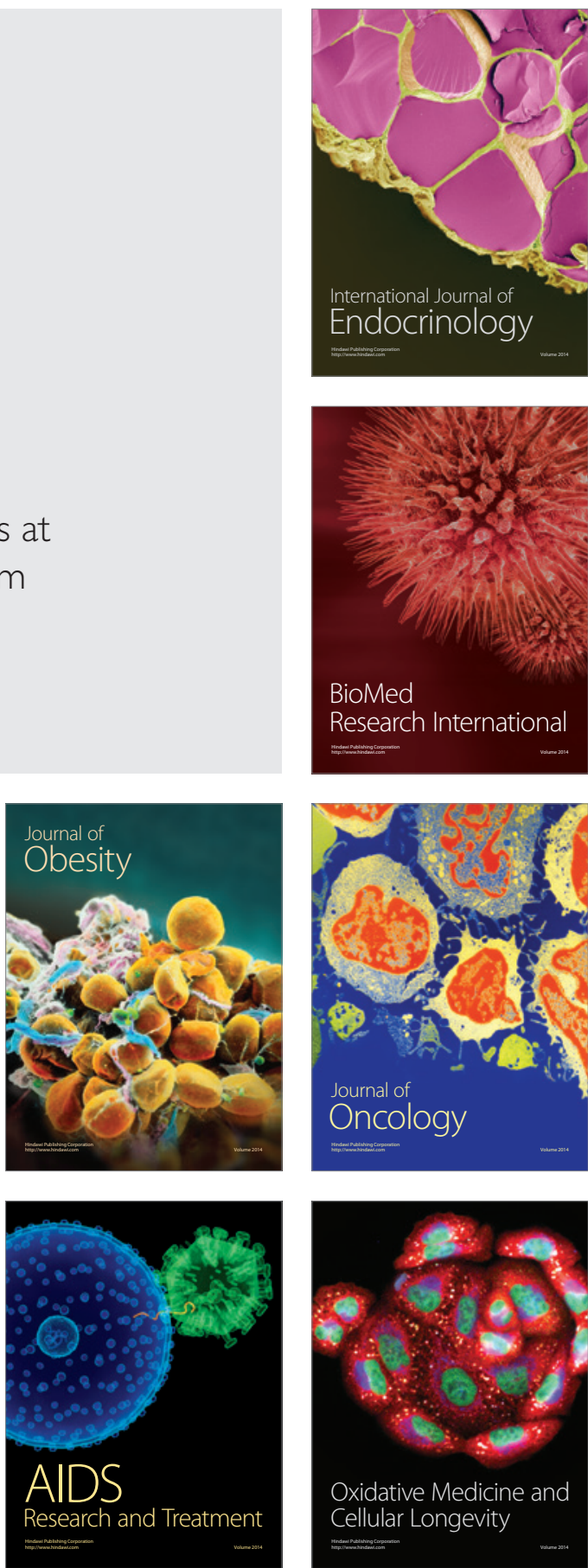